\title{
SISTEM INFORMASI MANAJEMEN TENAGA KERJA OUTSOURCING PADA PT. ACM BERBASIS JAVA
}

\author{
Sebastian Dwi Haristya Aryadi ${ }^{1}$, Aulia Paramita ${ }^{2}$ \\ 1,2, Teknik Informatika, Fakultas Teknik dan Ilmu Komputer, Universitas Indraprasta PGRI \\ Jalan Raya Temgah No. 80, Kelurahan Gedong, Pasar Rebo, Jakarta Timur

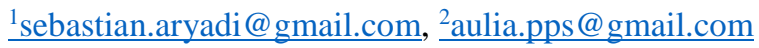

\begin{abstract}
ABSTRAK
Sejalan dengan perkembangan teknologi yang semakin maju dan pesat, menjadikan kebutuhan informasi semakin penting. Banyak perusahan dan instansi yang juga memanfaatkan informasi sebagai suatu sumber daya yang digunakan dalam kegiatannya. Peran komputer dan sistem sangat dibutuhkan untuk menunjang kegiatan tersebut. Sama halnya dengan PT. ACM yang merupakan perusahan jasa tenaga kerja outsourcing, yang mana pada sistem berjalan saat ini, masih menggunakan cara konvensional seperti pendataan pada kertas, yang mana selain memakan tempat serta rawan rusak dan hilang, juga membuat pencarian informasi memakan waktu yang lama. Tujuan penelitian ini adalah membangun sistem informasi manajemen tenaga kerja outsourcing menggunakan Java dan MySQL untuk mengatasi masalah pada sistem berjalan perusahaan. Metode penelitian yang digunakan adalah Research and Development (R\&D). Sedangkan metode pengembangan program yang dilakukan adalah menggunakan model Waterfall dari pendekatan System Development Life Cycle (SLDC). Penelitian ini menghasilkan sebuah rancangan Sistem Informasi Manajemen Tenaga Kerja Outsourcing yang diharapkan dapat membantu perusahaan dalam mengelola tenaga kerja outsourcing yang lebih baik, serta dapat meminimalisasi kerusakan dan kehilangan data, juga penyajian informasi yang lebih cepat, tepat, dan akurat.
\end{abstract}

Kata Kunci: Sistem Informasi, Manajemen, Tenaga Kerja, Outsourcing

\begin{abstract}
In line with the development of increasingly advanced and rapid technology, the need for information becomes increasingly important. Many companies and agencies also use information as a resource used in their activities. The role of computers and systems is needed to support these activities. It's the same with PT. ACM, which is an outsourced manpower service company, which in the current system, still uses conventional methods such as data collection on paper, which in addition to taking up space and prone to damage and loss, also makes searching for information take a long time. The purpose of this research is to build a system outsourced workforce management information using Java and MySQL to solve problems on the company's running system. The research method used is Research and Development (R\&D). While the program development method used is the Waterfall model from the System Development Life Cycle (SLDC) approach. This research resulted in a design of an Outsourcing Manpower Management Information System which is expected to help companies in better managing outsourced workers, as well as minimizing data damage and loss, as well as presenting information more quickly, precisely, and accurately.
\end{abstract}

Key Word: Information System, Management, Workforce, Outsourcing.

\section{PENDAHULUAN}

Sejalan dengan perkembangan teknologi yang semakin maju dan pesat, kebutuhan informasi menjadi semakin penting dalam tiap segi kehidupan masyarakat. Banyak perusahaan dan instansi yang juga memanfaatkan informasi sebagai suatu sumber daya yang digunakan untuk mengelola kegiatan transaksi di dalamnya. Dalam pengaplikasiannya tentu tak lepas dari peran komputer dan sistem. Salah satu sistem yang banyak digunakan adalah sistem manajemen tenaga kerja.
PT. Arsaval Central Mugitama (ACM) adalah sebuah perusahaan yang bergerak dibidang jasa tenaga kerja outsourcing jasa pengamanan. Dimana masalah yang dihadapi pada saat ini adalah perusahaan masih menggunakan cara konvensional dalam pendataan baik itu mencatat di kertas ataupun sekedar menggunakan Microsoft Office. Data yang diolah pun masih disimpan menggunakan dokumen-dokumen yang memakan tempat dan rawan rusak ataupun hilang. Selain itu, banyaknya penyimpanan tentunya akan membutuhkan waktu untuk 
pencarian datanya. Pembuatan laporan juga kurang praktis karena masih manual.

Maka dari itu, penulis mengusulkan untuk membuat sebuah sistem informasi manajemen tenaga kerja outsourcing yang diharapkan dapat mengatasi berbagai macam permasalahan yang dihadapi perusahaan.

Dalam melakukan penelitian, penulis mengambil referensi penelitian terkait dari jurnal yang berjudul Rancang Bangun Program Aplikasi Penempatan Tenaga Kerja Outsourcing. Dengan hasil yaitu, Progam Aplikasi Penempatan Tenaga Kerja Outsourcing ini dapat membantu bagian kepegawaian mencari data yang dibutuhkan secara cepat dan tepat waktu, mempermudah pelayanan kepada pihak yang memerlukan data dan mempermudah bagian kepegawaian dalam pengolahan data, dengan tidak membutuhkan waktu yang lama dalam pembuatan laporan. (Yusmawi et al., 2016).

Sistem dapat diartikan sebagai suatu kumpulan atau himpunan, unsur, komponen, atau variabel yang terorganisasi, berinteraksi, dan juga saling bergantung antara satu sama lain serta terpadu. (Sutabri, 2012b).

Informasi adalah data yang diolah menjadi bentuk yang berguna dan lebih berarti bagi penerimanya. Sumber informasi dari informasi sendiri adalah data, di mana dapat berupa kenyataan yang menggambarkan suatu kejadian pada saat tertentu dan kesatuan yang nyata. (Jeperson, 2014).

Manajemen dapat diartikan sebagai proses perencanaan, pengorganisasian, pengarahan, dan pengawasan terhadap usaha-usaha dari anggota organisasi dan juga penggunaan sumber daya di dalamnya agar mencapai tujuan untuk menghasilkan layanan atau produk. (Bob Foster, 2019).

Ousourcing atau alih daya adalah pemberian wewenang dari sebuah perusahaan ke perusahaan lainnya untuk menjalankan sebagian atau seluruh dari proses fungsi usaha dengan menetapkan suatu target atau tujuan tertentu. (Yasar, 2013).

Perancangan sistem informasi adalah suatu proses memahami sistem informasi yang kemudian dilanjutkan dengan membuat desain teknis berdasarkan evaluasi dari pemahaman tersebut yang mana nantinya akan digunakan sebagai dasar pengembangan sistem informasi yang lebih lanjut. (Santi, 2020).

Entity Relationship Diagram (ERD) adalah sebuah model data dimana di dalamanya menggunakan beberapa notasi yang menggambarkan data dalam hal entitas dan relasi yang digambarkan oleh data tersebut. (Hasugian \& Shidiq, 2012).

(Hastuti, 2018) menerangkan bahwa Java adalah bahasa pemrograman yang bisa dijalankan di berbagai komputer termasuk telepon genggam. Bahasa ini awalnya dibuat oleh James Gosling saat masih bergabung di Sun Microsystems yang mana merupakan bagian dari Oracle dan dirilis tahun 1995. Bahasa Java dijalankan menggunakan JVM atau Java Virtual Machine, hal ini menyebabkan Java lebih fleksibel dan bisa dijalankan di sistem operasi Windows, Mac OS atau Linux.

Tujuan dari penelitian ini adalah mengembangkan sebuah sistem informasi manajemen tenaga kerja outsourcing pada PT. ACM menggunakan Java untuk dapat membantu perusahaan dalam mengelola tenaga kerja outsourcing yang lebih baik.

\section{METODE PENELITIAN}

Dalam hal ini penulis menggunakan metode penelitian pengembangan atau R\&D (Research and Develompment) dalam melakukan penelitian.

Menurut (Setyosari, 2016), penelitian pengembangan adalah penelitian yang mana diarahkan untuk menghasilkan produk, desain dan proses. Dalam dunia pendidikan dan pembelajaran, penelitian pengembangan menitik fokuskan kajiannya dalam bidang desain atau rancangan yang berupa model desain juga desain bahan ajar ataupun produk.

Data Flow Diagram (DFD) atau Diagram Alir Data (DAD) adalah salah satu (network) yang menggambarkan sistem otomatis/ komputerisasi, manualisasi, atau gabungan dari pada keduanya, yang mana penggambarannya disusun dalam bentuk 
kumpulan komponen sistem yang saling berhubungan sesuai dengan aturan. (Sutabri, 2012a)

Dalam melakukan penelitian, penulis menggunakan model pengembangan sistem waterfall. Model waterfall atau model air terjun adalah pendekatan SDLC (System Development Life Cycle) yang paling awal digunakan untuk pengembangan perangkat lunak. Dalam model ini, setiap fase harus diselesaikan sebelum fase berikutnya dapat dimulai dan tidak ada fase yang tumpang tindih (Yusmawi et al., 2016).

Ruang lingkup penelitian antara lain dilakukan di PT. ACM dengan waktu penelitian kurang lebih empat bulan dimulai dari bulan April 2021. Kegiatan penelitian yaitu menganalisa data tenaga kerja, data klien, data pelatihan, data kontrak kerja, dan data penempatan. Menggunakan bahasa pemrograman Java yang didukung oleh aplikasi Netbeans dan database MySQL yang didukung oleh aplikasi XAMPP untuk pembuatan sistem.

Teknik pengumpulan data yang dilakukan antara lain dengan menggunakan metode wawancara, observasi, studi kepustakaan dan dokumentasi.

\section{HASIL DAN PEMBAHASAN}

Analisis sistem berjalan pada PT. ACM dapat digambarkan dengan menggunakan DAD dimana dapat dilihat mengenai arus data yang mengalir dari proses-proses yang berjalan pada perusahaan pada saat ini, yang djabarkan sebagai berikut:

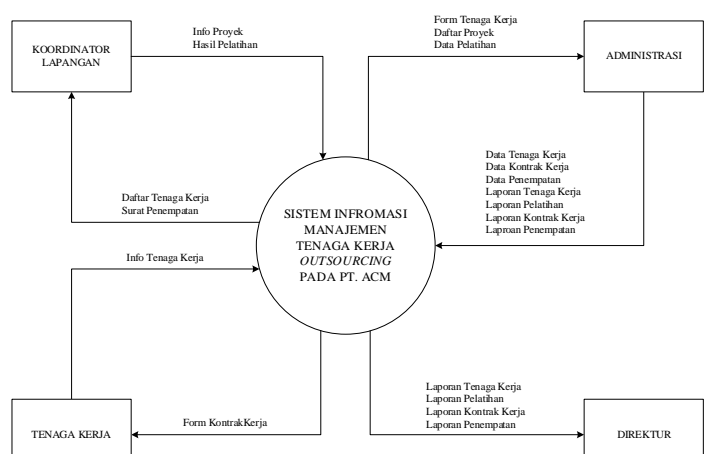

Gambar 1. Diagram Konteks Sistem Berjalan

Dari analisis sistem berjalan yang dilakukan, maka dapat disimpulkan bahwa permasalahan utama yang ada pada PT. ACM adalah masih banyak kegiatan perusahaan yang menggunakan cara konvensional dan komputer sebatas penggunaan Microsoft Excel untuk pendataan. Dan belum adanya sistem yang terkomputerisasi yang dapat membantu mengolah data secara baik dan terstruktur.

Maka dari itu penulis memberikan sebuah alternatif penyelesaian untuk masalah tersebut dengan Merancang sistem usulan dan membuat sistem informasi terkomputerisasi dengan database, yang mana digambarkan dalam DAD sistem yang diusulkan sebagai berikut:

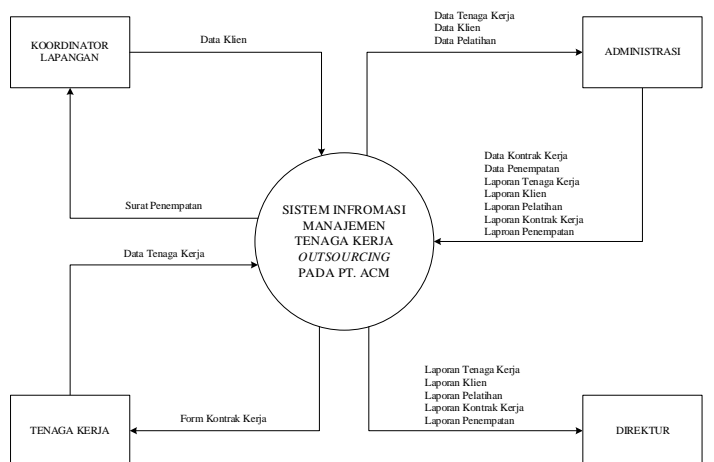

Gambar 2. Diagram Konteks Sistem Diusulkan

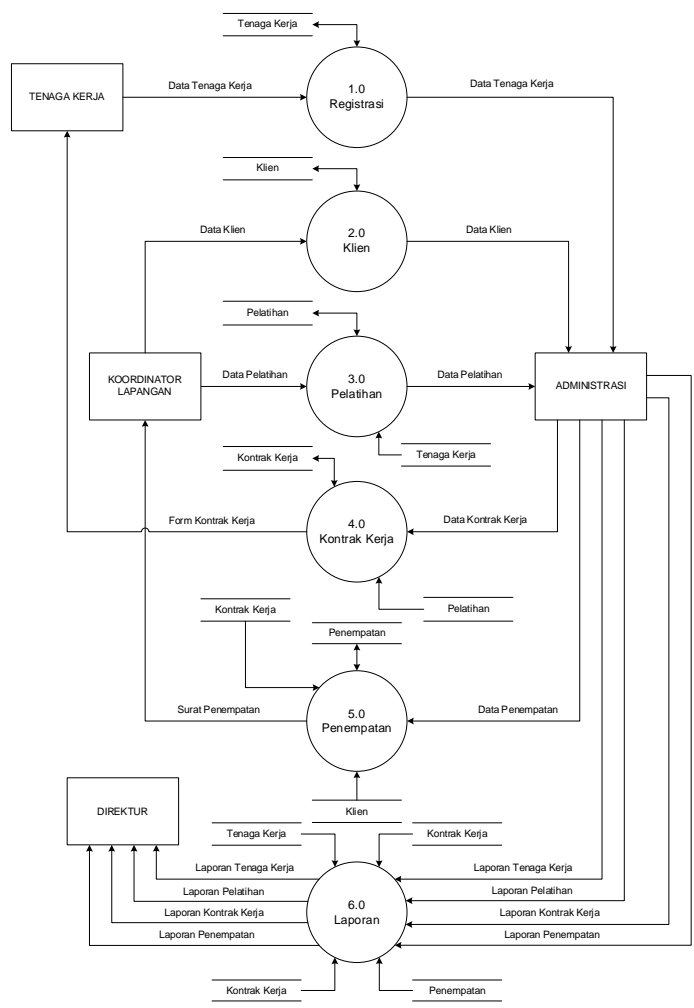

Gambar 3. Diagram Nol Sistem Diusulkan 
Rancangan basis data digunakan untuk dapat membuat database dengan baik dan tidak mengandung redundansi data. Langkah merancang basis data yang dilakukan antara lain adalah membuat Normalisasi, Entity Relationship Diagram (ERD), dan spesifikasi file basis data.

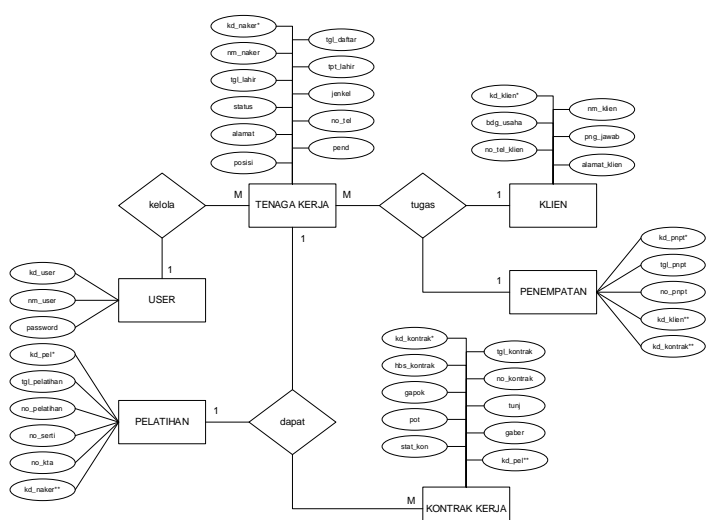

Gambar 4. Entity Relationship Diagram (ERD)

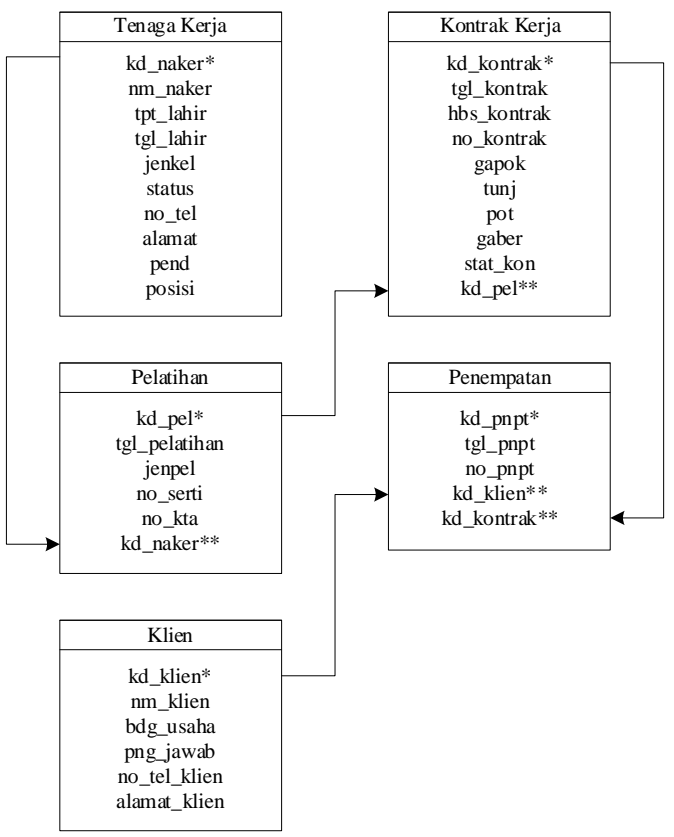

Gambar 5. Normalisasi 2NF

Rancangan dan tampilan untuk program yang dibuat menggunakan Netbeans sebagai salah satu Integrated Development Environtment (IDE) yang dapat membuat program berbasis Java. Berikut adalah hasil rancangan dan tampilan layar untuk program yang dibuat:

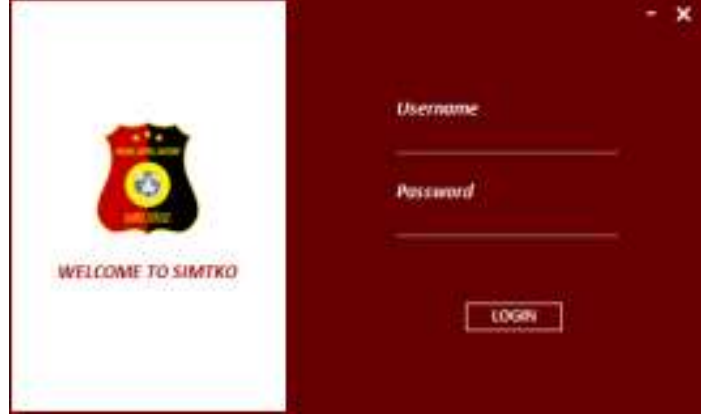

Gambar 6. Tampilan Layar Login

Layar Login ini akan muncul pada saat pertama kali aplikasi dijalankan. Pada layar ini pengguna harus memasukkan username dan password yang sesuai untuk mendapatkan akses masuk ke program.

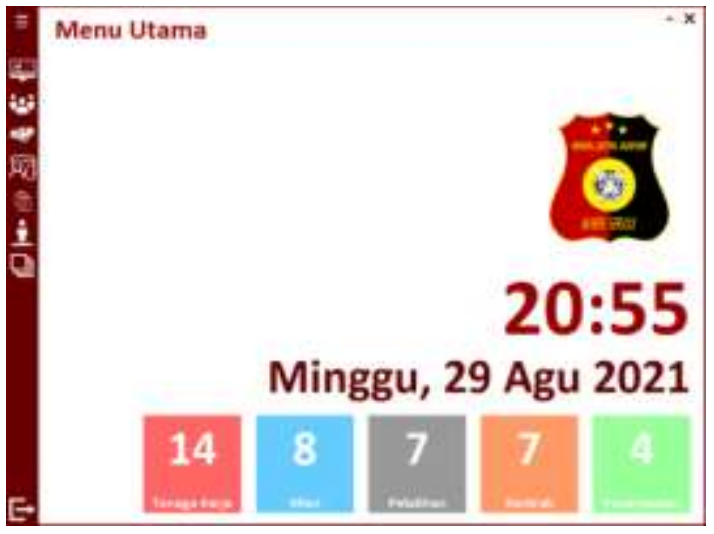

Gambar 7. Tampilan Layar Menu Utama

Tampilan layar Menu Utama ini akan muncul setelah pengguna berhasil mendapatkan akses dari layar Login. Di Menu Utama ini terdapat statistik dari data yang diolah oleh program.

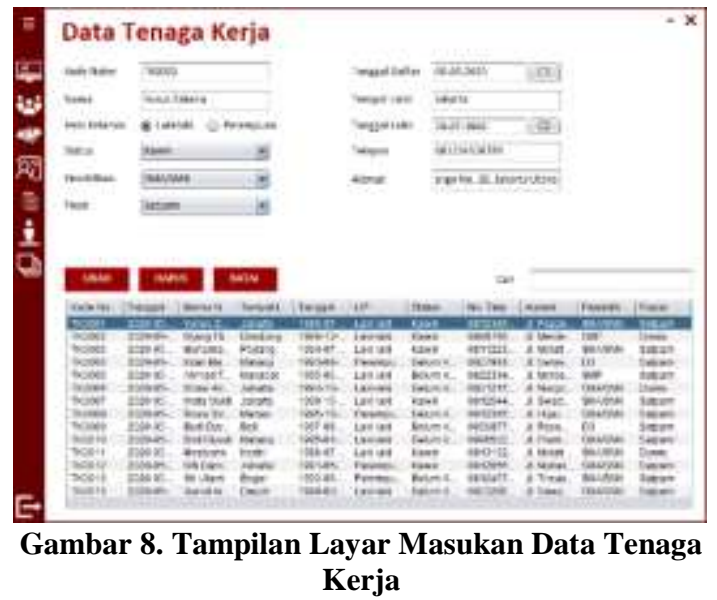

Tampilan layar masukan data tenaga kerja berfungsi untuk registrasi atau pendataan tenaga kerja yang baru. 


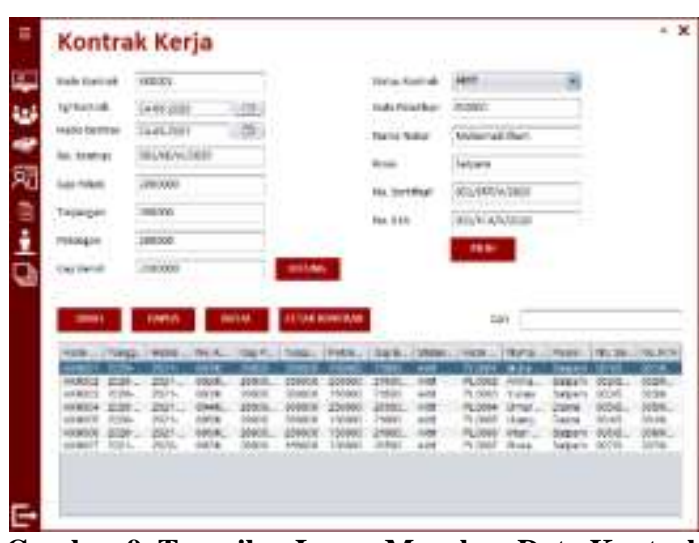

Gambar 9. Tampilan Layar Masukan Data Kontrak Kerja

Tampilan layar masukan data kontrak kerja berfungsi untuk pendataan kontrak kerja untuk tenaga kerja yang sudah menyelesaikan pelatihan. Pengguna juga dapat mencetak form kontrak kerja dengan memilih data lalu menekan tombol Cetak Kontrak.

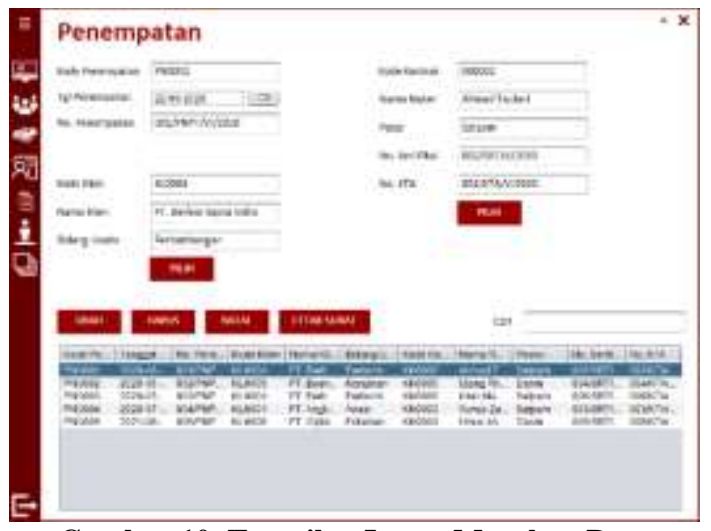

Gambar 10. Tampilan Layar Masukan Data Penempatan

Tampilan layar ini berfungsi untuk pendataan penempatan untuk tenaga kerja yang sudah menyelesaikan pelatihan, mempunyai sertifikat dan KTA, serta sudah mempunyai kontrak kerja. Di layar ini pengguna juga dapat mencetak surat penempatan dengan memilih data pada tabel data lalu menekan tombol Cetak Surat.

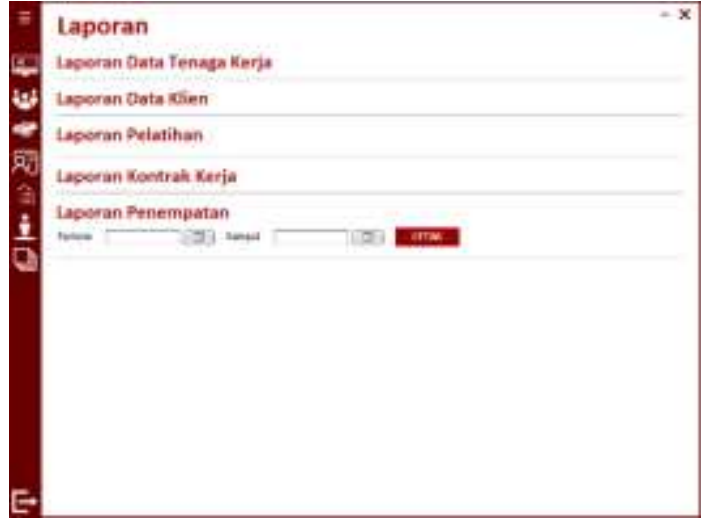

Gambar 11. Tampilan Layar Masukan Data Laporan

Tampilan layar ini berfungsi untuk pembuatan laporan untuk masing-masing data yang sudah dimasukkan dan diolah. Pengguna dapat memilih laporan jenis laporan yang ingin dibuat, lalu mencetak laporan tersebut.

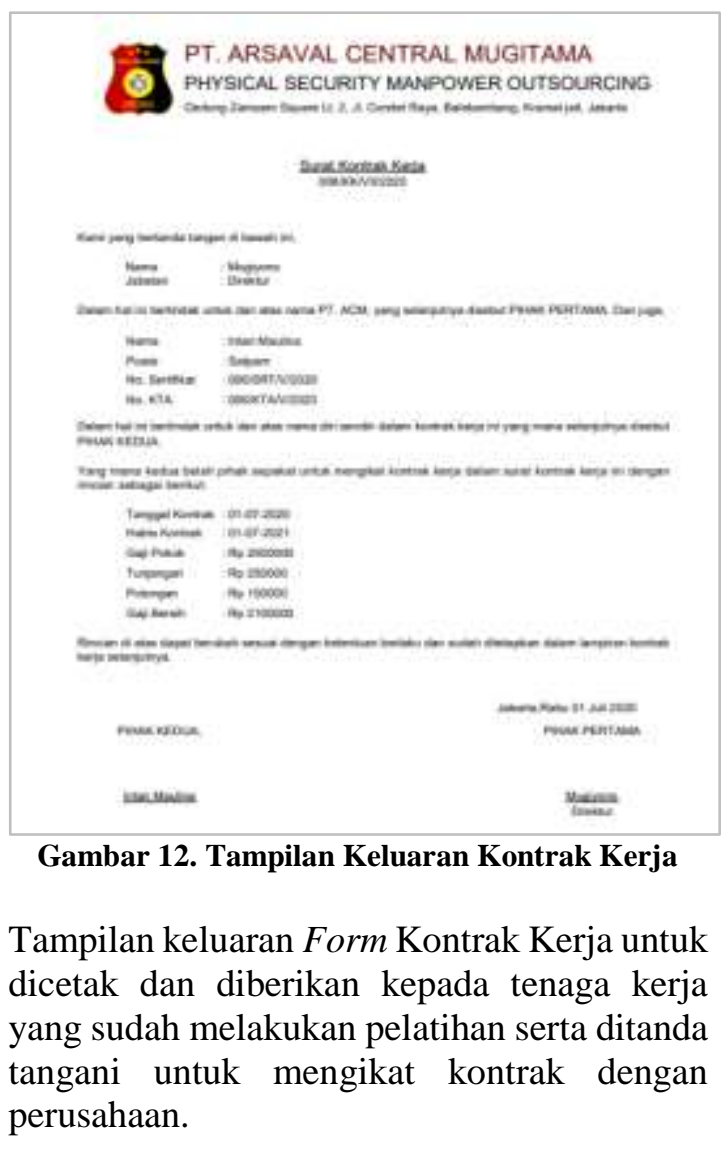




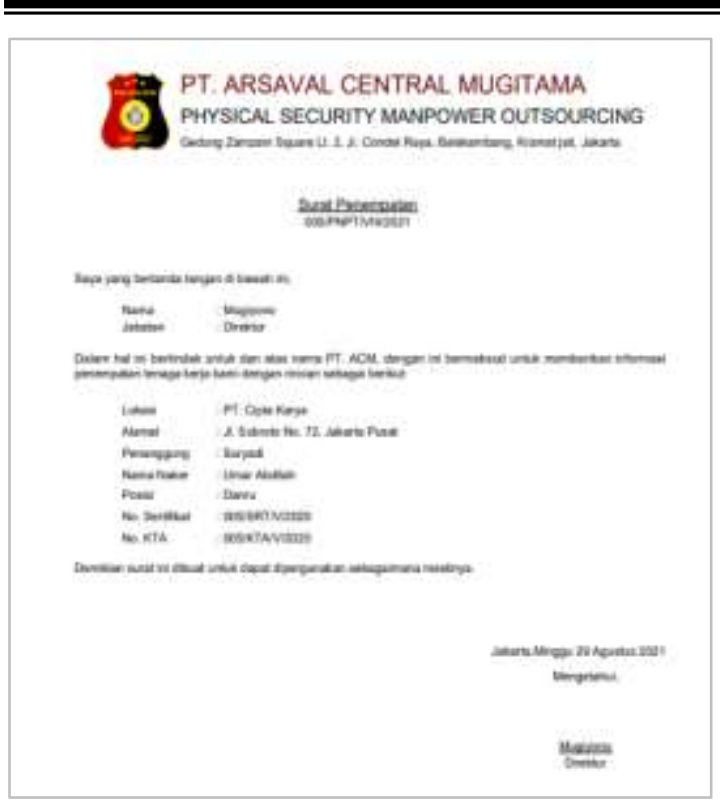

Gambar 13. Tampilan Keluaran Surat Penempatan

Tampilan keluaran Surat Penempatan untuk dicetak dan diberikan kepada koordinator lapangan yang mana akan digunakan sebagai pengantar tenaga kerja ke lokasi penempatan klien.

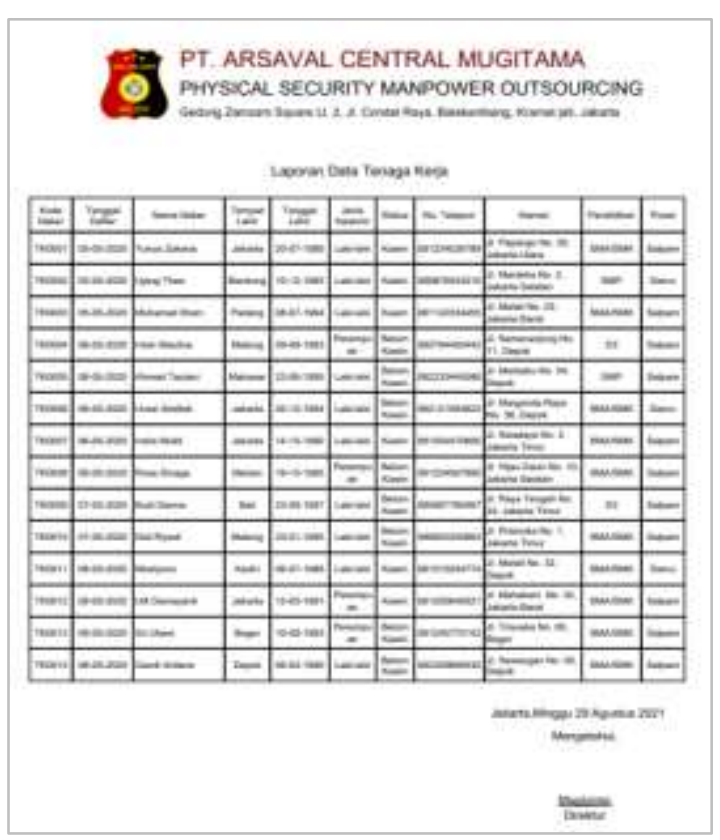

Gambar 14. Tampilan Keluaran Laporan Tenaga Kerja

Tampilan keluaran Laporan Tenaga Kerja untuk dicetak dan diberikan kepada direktur sebagai bukti registrasi atau pendataan tenaga kerja yang terdaftar pada perusahaan.

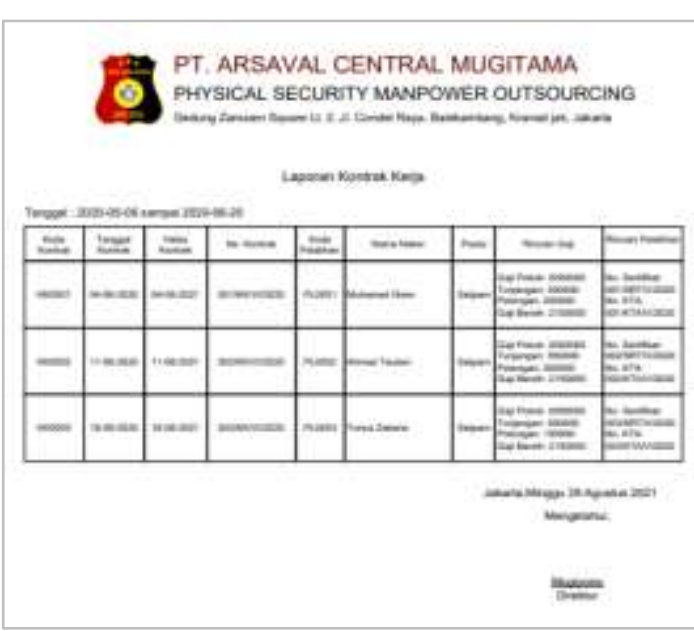

Gambar 15. Tampilan Keluaran Laporan Kontrak Kerja

Tampilan keluaran Laporan Kontrak Kerja untuk dicetak dan diberikan kepada direktur sebagai bukti kontrak kerja bagi tenaga kerja yang sudah mempunyai kontrak kerja dan terikat dengan perusahaan.

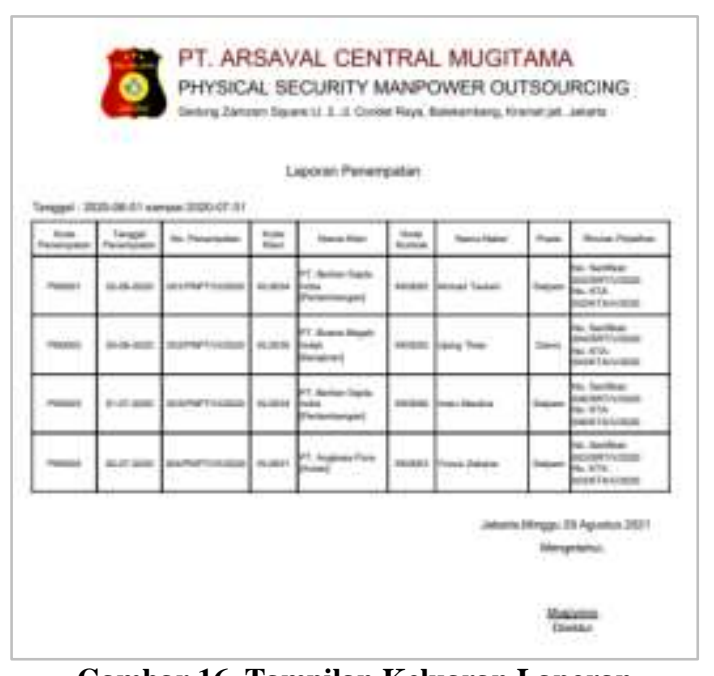

\section{Gambar 16. Tampilan Keluaran Laporan Penempatan}

Tampilan keluaran Laporan Penempatan untuk dicetak dan diberikan kepada direktur sebagai bukti penempatan tenaga kerja yang sudah ditempatkan ke lokasi penempatan.

\section{SIMPULAN DAN SARAN}

Dengan adanya sistem informasi manajemen tenaga kerja outsourcing pada PT. ACM diharapkan dapat meningkatkan efisiensi dari kegiatan yang dilakukan perusahan dimana pendataan dapat dilakukan dengan sistem terkomputerisasi dengan penyimpanan yang menggunakan database agar teratur dan aman sehingga dapat meminimalisasi penggunaan kertas yang terlalu banyak, juga pencarian dan 
penyajian informasi yang dibutuhkan dapat dilakukan dengan cepat dan efisien, serta pembuatan laporan tidak memakan waktu yang lama.

Walaupun sistem sudah terkomputerisasi dan menggunakan database, namun pengguna harus berhati-hati dalam menggunakan sistem terutama dari segi input data, agar tidak terjadi kesalahan. Keamanan sistem harus dijaga agar tidak disalahgunakan pihak yang tidak bertanggung jawab. Sistem informasi ini dapat dikembangkan untuk kedepannya seiring dengan kebutuhan perusahaan yang akan datang. Sistem perlu peninjauan dan pemeliharaan, terutama untuk back-up data pada database.

\section{DAFTAR PUSTAKA}

Bob Foster, I. S. (2019). Dasar-Dasar Manajemen. Dinda Kreatif.

Hastuti, D. \& Y. A. (2018). Belajar Pemrograman Java Menggunakan FX dan Database H2. Aswaja Pressindo.

Hasugian, H., \& Shidiq, A. N. (2012). Rancang Bangun Sistem Informasi Industri Kreatif Bidang Penyewaan Sarana Olahraga. Seminar Nasional Teknologi Informasi Dan Komunikasi Terapan (Semantik) 2012, 2012(Semantik 2012), 606-612. http://eprints.dinus.ac.id/202/

Jeperson, H. (2014). Konsep Sistem Informasi. Deepublish.

Santi, I. H. (2020). Analisa Perancangan Sistem. Nasya Expanding Management.

Setyosari, P. (2016). Metode Penelitian Pendidikan \& Pengembangan. Prenadamedia Group.

Sutabri, T. (2012a). Analisa Sistem Informasi. Andi.

Sutabri, T. (2012b). Konsep sistem informasi. Andi.

Yasar, I. (2013). Menjadi Karyawan Outsourcing. Gramedia.

Yusmawi, W., Putra, I., \& Syari, D. (2016). Rancang Bangun Program Aplikasi Penempatan Tenaga Kerja Outsourcing. Jurnal Ipteks Terapan, 9(2), 1-10. https://doi.org/10.22216/jit.2015.v9i2.3 6 